\title{
Filigrane
}

Écoutes psychothérapiques

\section{La langue vivante de la clinique psychanalytique}

\section{Le comité de rédaction}

Volume 18, numéro 2, automne 2009

Le corps. Sur le divan. Dans le fauteuil II

URI : https://id.erudit.org/iderudit/039293ar

DOI : https://doi.org/10.7202/039293ar

Aller au sommaire du numéro

Éditeur(s)

Revue Santé mentale au Québec

ISSN

1192-1412 (imprimé)

1911-4656 (numérique)

Découvrir la revue

Citer ce document

Le comité de rédaction (2009). La langue vivante de la clinique

psychanalytique. Filigrane, 18(2), 100-101. https://doi.org/10.7202/039293ar d'utilisation que vous pouvez consulter en ligne.

https://apropos.erudit.org/fr/usagers/politique-dutilisation/ 


\section{La langue vivante de la clinique psychanalytique. Argumentaire des dossiers 2011 de Filigrane}

\section{Le comité de rédaction}

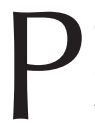

our sa $20^{\mathrm{e}}$ année de parution, Filigrane souhaite consacrer ses deux dossiers à la question de la langue, et convie ses auteurs à en interroger les enjeux pour les cliniciens d'aujourd'hui.

La langue, la lalangue, le langage, la parole. Celle que l'on prononce, celle que l'on entend, celle que l'on écoute, celle que l'on traduit. La langue et ses intrus, la langue du rêve, la langue des rébus, la langue et ses sous-entendus, le sens entendu. Entendre, comprendre, traduire, interpréter? La psychanalyse est depuis toujours attentive aux ratés, aux non-dits, aux silences, à la langue trouée de l'inconscient. Les mots pour le dire et pour le taire, le déguiser, le révéler. L'inconscient structuré comme un langage?

Dès l'origine, langue et psychanalyse sont indissociables: «talking cure» oblige. Mais il s'agit, on le sait, d'une langue bien particulière, celle qui est traversée, structurée par l'inconscient. Telle est notre langue commune, notre matériau de travail dans la rencontre analytique toujours au plus près du «Site de l'étranger» pour paraphraser Fédida.

Mais la langue de l'analysant, comme celle de l'analyste, est aussi véhicule de culture, d'histoire, de migrations, d'aliénation. Nous sommes toujours en présence de la langue de l' «autre » mais les migrations contemporaines confèrent à cette altérité une densité toute particulière. Que ce soit au sein du multiculturalisme des grandes villes occidentales ou par la fluidité des frontières désormais ouvertes, le psychanalyste est aujourd'hui confronté à un pluralisme langagier et à l'usage métissé de plusieurs langues. De quels cotés glisse la langue maternelle? Quelles voies peut ouvrir l'usage d'une langue étrangère en séance ? Les thérapeutes bilingues, voire polyglottes peuvent apporter un éclairage sur les impasses mais aussi sur les ouvertures qu'inaugurent ces jeux de langues.

Jusqu'à quel point la langue des psychanalystes est-elle prise dans les rets de la rectitude politique, des querelles idéologiques livrées à mots couverts? Pouvonsnous encore parler d'UNE langue psychanalytique? Parlons-nous encore la même langue ou sommes-nous en présence d'une nouvelle tour de Babel? 
Comment la scène du dehors, marquée par l'univers de la communication permanente et immédiate (courriel, texto, twitter) marque-t-elle la scène de la cure? Plus gravement peut-être, comment résonnent aujourd'hui les langues de l'agir et de la désubjectivation pour le clinicien toujours à l'écoute ? Enfin, certains se préoccupent d'une possible désaffection des jeunes à l'égard de la psychanalyse et de sa (ses) langue(s).

Est-ce que ça parle encore?

Date de tombée des textes: $1^{\text {er }}$ septembre 2010; longueur approximative des textes: 15 feuillets; adresse courriel où faire parvenir le fichier du texte: gilbert.sophie@uqam.ca ou lussier.veronique@uqam.ca 